\title{
Intravenous Self-Administration of the Indirect Dopaminergic Agonist Amfonelic Acid by Rats ${ }^{1}$
}

\author{
LINDA J. PORRINO,${ }^{2}$ NANCY L. GOODMAN AND LAWRENCE G. SHARPE \\ Neuropsychopharmacology Laboratory, Preclinical Pharmacology Branch \\ Addiction Research Center, National Institute on Drug Abuse \\ P.O. Box 5180, Baltimore, MD 21224
}

Received 3 March 1988

\begin{abstract}
PORRINO, L. J., N. L. GOODMAN AND L. G. SHARPE. Intravenous self-administration of the indirect dopaminergic agonist amfonelic acid by rats. PHARMACOL BIOCHEM BEHAV 31(3) 623-626, 1988.-The reinforcing properties of amfonelic acid, a nonamphetamine psychostimulant, were evaluated in an intravenous self-administration paradigm. Rats were trained to self-administer cocaine $(0.5-3.0 \mathrm{mg} / \mathrm{kg} /$ infusion) on a fixed-ratio 10 schedule of reinforcement via surgically implanted intravenous catheters during daily 4 - $\mathrm{hr}$ sessions. Substitution of amfonelic acid $(0.0625-0.250 \mathrm{mg} / \mathrm{kg} / \mathrm{infusion})$ reliably maintained self-administration in a dose-dependent manner. These data indicate that amfonelic acid can act as a reinforcer in rats, and further suggest that amfonelic acid may have abuse potential in humans.
\end{abstract}

Self-administration Psychomotor stimulants Amfonelic acid Cocaine Dopamine

AMFONELIC acid (AFA) is a psychostimulant which acts as an indirect dopaminergic agonist $(1,2)$. AFA, like other similar drugs such as amphetamine and cocaine, increases the levels of catecholamines in the synaptic cleft. It is, however, a nonamphetamine psychostimulant in that its actions are blocked by reserpine rather than alpha-methyl-paratyrosine which blocks the actions of amphetamine-like psychostimulants (2). In this respect, AFA is more like cocaine and methylphenidate in its biochemical actions. In addition, at low doses AFA is thought to be more specific to dopaminergic systems $(12,26)$, having little or no action on noradrenergic $(10,17)$ or serotinergic neurons $(29)$.

Behaviorally, AFA has actions quite similar to other psychomotor stimulants. At low doses, for example, AFA stimulates locomotor behavior, whereas at higher doses stereotypic behavior is elicited $(4,14)$. Furthermore, the discriminative stimulus properties of AFA have been shown to generalize to both cocaine (24) and amphetamine $(3,23,24)$. Finally, AFA lowers the threshold for rewarding brain stimulation $(13,15)$ in a manner similar to cocaine (7) and amphetamine $(8,27)$ suggesting that AFA, like other psychostimulants, can have effects on central reinforcement systems.

The purpose of the present study was to investigate further the reinforcing properties of AFA using the intravenous self-administration paradigm in rats. The selfadministration paradigm is one of the most widely used and accepted means of assessing the reinforcing properties of a given drug, as well as providing information about a drug's potential for abuse. AFA was tested in this paradigm to determine if it would be self-administered in a manner similar to other psychostimulants [cf. $(19,21,25)$ ].

METHOD

\section{Animals}

Male Lewis rats (Charles River, Fredrick, MD) weighing $300-350 \mathrm{~g}$ at the start of the experiment were housed individually and placed on a $12 \mathrm{hr}$ light/dark cycle (lights on/off 7 a.m. $/ 7$ p.m.) under controlled temperature and humidity conditions. Food and water were available ad lib. Under pentobarbital anesthesia $(50 \mathrm{mg} / \mathrm{kg}$ ) chronic indwelling silastic catheters were surgically implanted in the external jugular vein according to procedures described by Weeks (30).

\section{Apparatus}

All testing was conducted in BRS/LVE (Laurel, MD) operant chambers $(30 \times 25 \times 27 \mathrm{~cm})$ enclosed in ventilated, sound-attenuated cubicles. Two response levers were mounted on one wall, $17 \mathrm{~cm}$ apart and $5 \mathrm{~cm}$ above the grid floor. Pressing of the left lever resulted in the activation of an automatic infusion pump (Sage Model 355; Sage Instruments, Cambridge, MA). Intravenous (IV) infusions were deliv-

\footnotetext{
${ }^{1}$ A preliminary report of this work was presented at the 17 th Annual Society for Neuroscience meeting held in New Orleans, LA, November, 1987 (11).

${ }^{2}$ Requests for reprints should be addressed to Linda J. Porrino at her present address: Unit on Brain Imaging, Clinical Neuroscience Branch, National Institute of Neurological and Communicative Disorders and Stroke, 9000 Rockville Pike, Bldg. 10, Room 5N-214, Bethesda, MD 20892.
} 


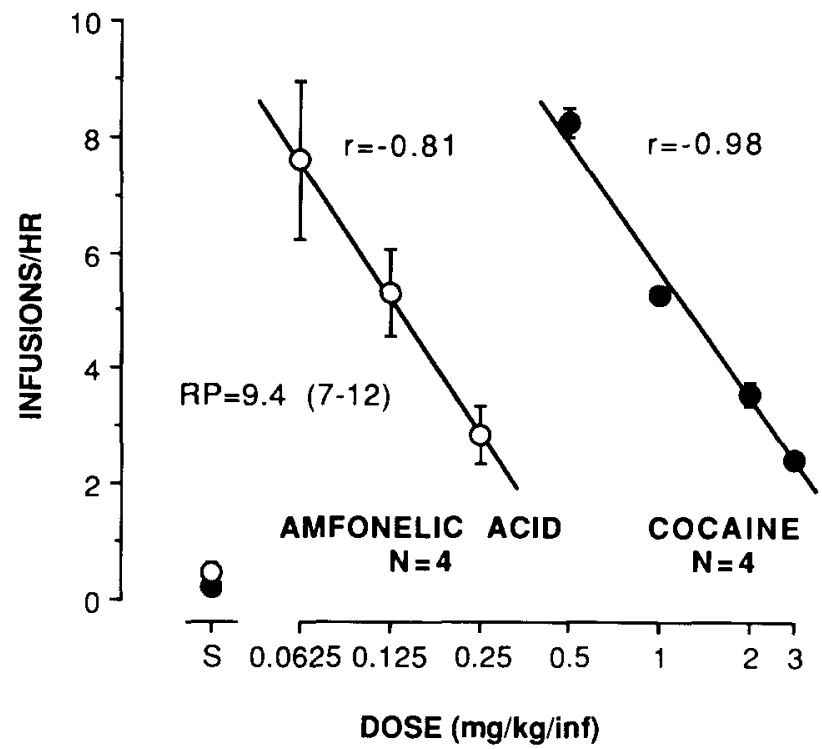

FIG. 1. Dose-dependent responding (FR10) maintained by amfonelic acid $(O)$ and cocaine $(\mathbf{O})$. Both correlation coefficients $(r)$, determined by linear regression analysis, were statistically significant $(p<0.005)$. $\mathbf{R P}=$ relative potency estimates with lower and upper $95 \%$ confidence limits in parentheses (9). Relative potency estimates here can be interpreted to mean that similar rates of self-injection of amfonelic acid were maintained with doses 9.4 times lower than that of cocaine

ered from the pump via Tygon tubing (Fisher Scientific Co., Springfield, NJ) to a swivel and from the swivel through spring-covered plastic tubing (Alice King Chatham, Los Angeles, CA) to the rat. Responding on both levers was recorded, although only responding on the left lever had programmed consequences. Schedule contingencies were programmed and data recorded by a SKED-11 computer system (State Systems Inc., Kalamazoo, MI). Information on the temporal distribution of responses within each experimental session was recorded with event recorders (Gerbrands, Arlington, MA).

\section{Procedure}

Following a minimum of seven days after surgery, each rat was given access to the levers the depression of one of which produced a $75 \mu \mathrm{l}$ IV infusion of cocaine (1.0 $\mathrm{mg} / \mathrm{kg} /$ infusion) lasting 5 seconds. All sessions were $4 \mathrm{hr}$ in duration. During the first 2 weeks following the acquisition of self-administration, the response requirement was increased from 1 to 10 per infusion (fixed-ratio 10). After stable responding (less than $10 \%$ variation in infusion rate per hour per session for 3 consecutive sessions) was established on the fixed-ratio 10 schedule, a different dose of cocaine $(0.5$, 2.0 , or $3.0 \mathrm{mg} / \mathrm{kg} / \mathrm{inf}$ ) was substituted in random order for a minimum of 3 sessions at each dose. In addition, $0.9 \%$ saline was substituted until responding was consistent at low levels (usually only 1-2 sessions). When responding maintained by $1.0 \mathrm{mg} / \mathrm{kg} /$ inf cocaine had returned to baseline levels, AFA was substituted. Three doses of AFA, $0.0625,0.125$, and $0.25 \mathrm{mg} / \mathrm{kg} / \mathrm{inf}$, were chosen on the basis of previous work with AFA in other paradigms $(13,15,24)$. The 0.125 $\mathrm{mg} / \mathrm{kg} / \mathrm{inf}$ dose of AFA was tested first; and AFA, 0.25 $\mathrm{mg} / \mathrm{kg} / \mathrm{inf}$, was infused over $10 \mathrm{sec}$ because of poor solubility. A minimum of 3 sessions were run at each dose.
\# 1007

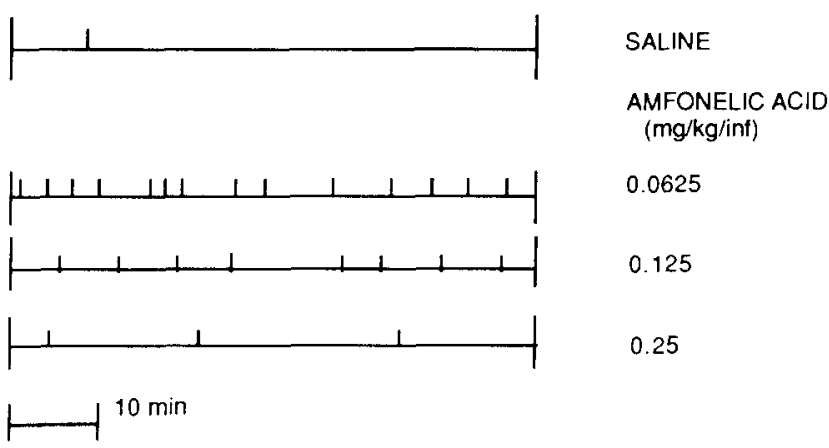

FIG. 2. Event records of self-injections of saline and amfonelic acid $(0.0625,0.125,0.250 \mathrm{mg} / \mathrm{kg} /$ infusion) during comparable one-hour segments of 4-hour test sessions by a rat previously trained to selfadminister cocaine. Responding was maintained on an FR10 schedule of reinforcement. Each vertical line represents one selfinjection.

\section{Statistical Analysis}

The data were calculated as infusions/hr and statistical methods for parallel line bioassay (9) were used to compare cocaine and AFA self-administration. Linear regression analysis was calculated for doses of both drugs.

Drugs

AFA (Research Biochemicals Inc., Natick, MA) was prepared by dissolving the drug in a dilute $\mathrm{NaOH}$ saline solution with $\mathrm{pH}$ adjusted to 9-10 with $1 \mathrm{~N} \mathrm{HCl}$. Solutions were prepared fresh daily. Cocaine $\mathrm{HCl}$ (National Institute on Drug Abuse) was dissolved in saline.

\section{RESULTS}

Cocaine at each of the four doses tested maintained stable rates of responding above saline infusion rates in each animal tested (Fig. 1). A clear dose-dependent relationship was evident in that the number of infusions per hour decreased as the dose of cocaine increased. When AFA was substituted for cocaine, rates of responding for AFA were higher than for saline at each dose tested (Fig. 1). Within the dose range tested, there was again a dose-dependent relationship with higher rates of responding maintained by lower doses of AFA. Both cocaine and AFA showed significant linear trends $(p<0.005)$ with no significant deviation from linearity. Within the dose range tested for each drug, bioassay analysis revealed that the dose-effect curves were parallel. In addition, AFA produced comparable infusion rates at doses 9.4 times lower than cocaine (Fig. 1). Mean total cocaine intake over the $4 \mathrm{hr}$ sessions ranged from $9.87 \mathrm{mg}$ at the 0.5 $\mathrm{mg} / \mathrm{kg} / \mathrm{inf}$ dose to $15.32 \mathrm{mg}$ at the $3.0 \mathrm{mg} / \mathrm{kg} / \mathrm{inf}$ dose. Mean total intake of AFA over the 4-hr sessions ranged from 1.14 $\mathrm{mg}$ at the $0.0625 \mathrm{mg} / \mathrm{kg} / \mathrm{inf}$ dose to $1.70 \mathrm{mg}$ at the 0.25 $\mathrm{mg} / \mathrm{kg} / \mathrm{inf}$ dose. Again, AFA intake was approximately 9 times lower than cocaine at comparable doses.

The temporal pattern of self-injections of AFA for a representative animal is shown in Fig. 2. This animal exhibited fairly constant rates of self-administration of AFA across time, providing further evidence for the dosedependent self-administration of AFA. In addition, rates of responding on the nonreinforced lever were unaffected by 
changes in drug dose or by substitution of AFA for cocaine, and remained at low levels (less than 1 per hour) during all test sessions.

\section{DISCUSSION}

The nonamphetamine psychostimulant, AFA, reliably maintained intravenous self-administration in each of the rats tested in this study. The rate of responding maintained by AFA self-injections was inversely related to the dose of the AFA, as is the case with other self-administered drugs [cf. (20)]. This strongly suggests that AFA, like cocaine and other psychostimulants such as amphetamine $(19,21,25)$, has positive reinforcing properties. Furthermore, these data confirm results obtained using another frequently used animal model for the assessment of the reinforcing efficacy of drugs, intracranial self-stimulation. AFA lowers the threshold for electrical brain stimulation reward indicating an increased sensitivity of central reward processes $(13,15)$. This threshold lowering effect is similar to that seen with other drugs of abuse such as cocaine and morphine $(6,7)$.

The parallel dose-effect curves for cocaine and AFA obtained in the present study suggest that at least in this paradigm these two drugs may be acting through similar mechanisms. Approximately a 9 times greater dose of cocaine, however, was required to maintain equivalent rates of self-administration. The similar mode of action shared by cocaine and AFA with regard to their reinforcing properties is likely to be the result of effects on dopaminergic systems. Both drugs are indirect dopamine agonists which increase the concentrations of synaptic dopamine by, at least in part, releasing dopamine from neuronal granular storage pools, although cocaine also has significant effects on dopamine reuptake (16). In addition, AFA within the dose range of the present study has little or no effect on neurotransmitter systems other than dopamine $(12,17,26,29)$. It seems clear, then, that like cocaine $(5,22)$ the reinforcing properties of AFA are also dopamine-dependent.

In other behavioral paradigms, similarities between the effects of AFA and other psychostimulants have also been demonstrated. AFA, for example, stimulates locomotor and elicits stereotypic behavior patterns $(1,4)$, phenomenologically similar to those elicited by amphetamine (14). AFA also produces significant increases in ipsilateral circling behavior in animals with unilateral 6-hydroxydopamine lesions of the dopaminergic nigrostriatal system $(14,28)$ comparable to those produced by other drugs with presynaptic dopaminergic actions (e.g., amphetamine, methylphenidate, pipradrol). Furthermore, in studies of the discriminative stimulus properties of dopaminergic drugs, stimulus generalization was seen between AFA and amphetamine and cocaine, but not apomorphine $(3,23,24)$. Cocaine produced a parallel doseresponse curve to AFA when AFA was the training drug, but was 6 times less potent that AFA (24). This is in contrast to the estimate of 9 times obtained in the present study of selfadministration behavior.

In summary, the present data demonstrating that AFA is reliably self-administered are clear evidence that AFA has reinforcing properties similar to those of cocaine. Furthermore, they suggest that AFA may have potential for abuse in humans.

\section{ACKNOWLEDGEMENT}

The authors would like to thank Dory Feldman for her expert editorial assistance in the preparation of this manuscript.

\section{REFERENCES}

1. Aceto, M. D.; Botton, I.; Levitt, M.; Martin, R.; Bentley, H. C.; Speight, P. T. Pharmacologic properties and mechanism of action of amfonelic acid. Eur. J. Pharmacol. 10:344-354; 1970.

2. Aceto, M. D.; Harris, L. S.; Lesher, G. Y.; Pearl, J.; Brown, T. G. Pharmacological studies with 7-benzyl-1-ethyl-1,4-dihydro6-oxo-1,8-naphthyridine-3-carboxylic acide. J. Pharmacol. Exp. Ther. 158:286-293; 1967.

3. Aceto, M. D.; Rosecrans, J. A.; Young, R.; Glennon, R. A. Similarity between $(+)$-amphetamine and amfonelic acid. Pharmacol. Biochem. Behav. 20:635-637; 1984.

4. Braestrup, C. Biochemical differentiation of amphetamine versus methylphenidate and nomifensine in rats. J. Pharm. Pharmacol. 29:463-470; 1977.

5. DeWit, H.; Wise, R. A. Blockade of cocaine reinforcement in rats with the dopamine blocker pimozide but not with the noradrenergic blockers phentolamine or phenoxybenzamine. Can. J. Psychol. 31:195-203; 1977.

6. Esposito, R. U.; McLean, S.; Kornetsky, C. Effects of morphine on intracranial self-stimulation to various brain stem loci. Brain Res. 168:425-429; 1979.

7. Esposito, R. U.; Motola, A. H. D.; Kornetsky, C. Cocaine: Acute effects on reinforcement thresholds for self-stimulation behavior to the medial forebrain bundle. Pharmacol. Biochem. Behav. 8:437-439; 1978.

8. Esposito, R. U.; Perry, W.; Kornetsky, C. Effects of d-amphetamine and naloxone on brain stimulation reward. Psychopharmacology (Berlin) 69:187-191; 1980.

9. Finney, D. J. Statistical methods in biological assay. New York: Hafner; 1964.

10. German, D. C.; Sanghera, M. K.; Kiser, R. S.; McMillen, B. A.; Shore, P. A. Electrophysiological and biochemical responses of noradrenergic neurons to a non-amphetamine CNS stimulant. Brain Res. 166:331-339; 1979.
11. Goodman, N. L.; Porrino, L. J. Intravenous self-administration of the indirect dopamine agonist amfonelic acid. Soc. Neurosci. Abstr. 13:1322; 1987.

12. Heikkila, R. E.; Manzino, L. Behavioral properties of GBR 12909, GBR 13069 and GBR 13098: Specific inhibitions of dopamine uptake. Eur. J. Pharmacol. 103:241-248; 1984.

13. Izenwasser, S.; Kornetsky, C. The effect of amfonelic acid or nisoxetine in combination with morphine in brain-stimulation reward. Pharmacol. Biochem. Behav. 32(4):in press; 1989.

14. Jeste, D. V.; Perlow, M. J.; Wyatt, R. J.; Stoff, D. M. Behavioral effects of amfonelic acid in rats: A comparison with amphetamine and apomorphine. Commun. Psychopharmacol. $3: 41-47 ; 1979$.

15. Knapp, C. M.; Kornetsky, C. The effects of amfonelic acid alone and in combination with naloxone brain-stimulation reward. Pharmacol. Biochem. Behav. 32(4):in press; 1989.

16. McMillen, B. A. CNS stimulants: Two distinct mechanisms of action for amphetamine-like drugs. Trends Pharmacol. Sci. 4:429-432; 1983.

17. McMillen, B. A.; Shore, P. A. Amfonelic acid, a nonamphetamine stimulant, has marked effects on brain dopamine metabolism but not noradrenaline metabolism: association with differences in neuronal storage systems. J. Pharm. Pharmacol. 30:464-466; 1978

18. Moore, K. E.; Chuieh, C. C.; Zeldes, G. Release of neurotransmitters from the brain in vivo by amphetamine, methylphenidate and cocaine. In: Ellinwood, E. H.; Kilbey, M. M., eds. Cocaine and other stimulants, New York: Plenum Press; 1977:143-260.

19. Nielsen, J. A.; Duda, N. J.; Mokler, D. J.; Moore, K. E. Selfadministration of central stimulants by rats: A comparison of the effects of d-amphetamine, methylphenidate and McNeil 4612. Pharmacol. Biochem. Behav. 20:227-232; 1984. 
20. Pickens, R.; Thompson, T. Cocaine-reinforced behavior in rats: Effects of reinforcement magnitude and fixed-ratio size. J. Pharmacol. Exp. Ther. 161:122-129; 1968.

21. Pickens, R.; Harris, W. C. Self-administration of amphetamine by rats. Psychopharmacologia 12:158-163; 1968.

22. Roberts, D. C. S.; Corcoran, M. E.; Fibiger, H. C. On the role of ascending catecholaminergic systems in intravenous selfadministration of cocaine. Pharmacol. Biochem. Behav. 6:615$620 ; 1977$.

23. Schechter, M. D. Different dopaminergic mechanisms for amfonelic acid, amphetamine and apomorphine. Pharmacol. Biochem. Behav. 13(4):497-500; 1980.

24. Schechter, M. D. Amfonelic acid: Similarity to other dopamine agonists. Pharmacol. Biochem. Behav. 26:413-416; 1987.

25. Schuster, C. R.; Thompson, T. Self-administration of and behavioral dependence on drugs. Annu. Rev. Pharmacol. 9:483$502 ; 1969$.
26. Shore, P. A. Actions of amfonelic acid and other nonamphetamine stimulants on the dopamine neuron. J. Pharm. Pharmacol. 28:855-857: 1976.

27. Stein, L.; Ray, O. S. Brian stimulation reward "thresholds" self-determined in rat. Psychopharmacologia 1:251-256; 1960.

28. von Voigtlander, T. F.; Moore, K. E. Turning behavior of mice with unilateral 6-hydroxydopamine lesions in the striatum: Effects of apomorphine, L-DOPA amantadine, amphetamine and other psychomotor stimulants. Neuropharmacology 12:451$462 ; 1973$.

29. Waldmeier, P. C.; Buchle, A. M.; Stoecklin, K.: Fehr, B.; Feldtrauer, J.-J. The effects of amfonelic acid on 5-HT metabolism in rat brain. J. Neural Transm. 57:149-165: 1983.

30. Weeks, J. R. Long-term intravenous infusion. In: Myers, R. D., ed. Methods in psychobiology. vol. 2, London: Academic Press: 1972:155-168. 